\title{
Long-term bonding to eroded dentin requires superficial bur preparation
}

\author{
Brigitte Zimmerli • Jan De Munck • Adrian Lussi • \\ Paul Lambrechts • Bart Van Meerbeek
}

Received: 9 March 2011 / Accepted: 21 November 2011 /Published online: 8 December 2011

(C) The Author(s) 2011. This article is published with open access at Springerlink.com

\begin{abstract}
Objectives This study aims to evaluate the influence of different surface preparation techniques on long-term bonding effectiveness to eroded dentin.

Materials and methods Dentin specimens were eroded by $\mathrm{pH}$ cycling or were left untreated as control, respectively. Five different "preparation" techniques were applied: (1) cleaning with pumice, (2) air abrasion, (3) silicon polisher, (4) proxo-shape, and (5) diamond bur. The three-step etchand-rinse adhesive OptiBond FL (O-FL; Kerr) and the mild two-step self-etch adhesive Clearfil SE Bond (C-SE; Kuraray) were evaluated. Micro-tensile bond strength was measured after water storage for $24 \mathrm{~h}$ and 1 year. Fracture analysis was performed by stereomicroscopy and SEM. Interfaces were characterized by TEM. Differences were statistically analyzed with a linear mixed effects model $(\alpha=0.05)$. Results Erosion reduced bond strength in all groups, but this effect was less prominent when eroded dentin was prepared by diamond bur. Storage lowered bond strength in almost all groups significantly, but this ageing effect was more prominent for the eroded surfaces than for non-eroded controls.
\end{abstract}

\footnotetext{
B. Zimmerli · J. De Munck · P. Lambrechts • B. Van Meerbeek Leuven BIOMAT Research Cluster, Department of Conservative Dentistry, School of Dentistry, Oral Pathology and Maxillo-Facial Surgery, Catholic University of Leuven, Leuven, Belgium

B. Zimmerli $\cdot$ A. Lussi

Department of Preventive, Restorative and Pediatric Dentistry, School of Dental Medicine, University of Bern,

Bern, Switzerland

B. Zimmerli $(\bowtie)$

Klinik für Zahnerhaltung,

Freiburgstrasse 7,

CH-3010 Bern, Switzerland

e-mail: brigitte.zimmerli@zmk.unibe.ch
}

Whereas after 1-year control specimens revealed superior bond strength with the three-step etch-and-rinse adhesive (O-FL), the mild two-step self-etch adhesive (C-SE) revealed a better 1-year bond strength to eroded dentin. The interface at eroded dentin appeared very prone to degradation as was shown by the increased amount of adhesive failures and by the silver infiltration detected by TEM.

Conclusions and clinical relevance Although a minimally invasive approach should clinically always be strived for, superficial preparation (or minimal roughening) with a diamond bur is recommendable for long-term bonding to eroded dentin.

Keywords Erosion · Adhesives $\cdot$ Micro-tensile bond strength · Preparation · Storage

\section{Introduction}

A higher incidence of erosive lesions has been recorded in patients of, in particular, industrialized countries. An altered diet and increase in gastro-esophageal disorders are regarded as main reasons [1-3].

One of the main options to treat erosive lesions with exposed (and thus often sensitive) dentin consists of covering them with a sealant or adhesive so that further loss of tooth substance can be prevented [4-7]. There are however only few studies dealing with adhesive properties on eroded dentin surfaces. Although one clinical study reported good retention of class $\mathrm{V}$ restorations bonded to unprepared eroded dentin for 12 months [8], another investigation showed a high loss rate of even $44-50 \%$ [9].

At the moment, no clear guidelines are available on how erosive lesions are best prepared to achieve the most durable bond. Moreover, other studies revealed that cavity preparation might affect bond strength of different types of adhesive 
differently [10-14]. Therefore, the working hypotheses tested in this study were:

1. There were no differences in bonding effectiveness to eroded and non-eroded dentin surfaces irrespective of which surface preparation technique was employed.

2. One-year water storage affected the bond strength to eroded and non-eroded dentin similarly.

\section{Materials and methods}

\section{Sample preparation and $\mathrm{pH}$ cycling}

Freshly extracted human molars were collected and stored in a saturated chloramine solution at $5^{\circ} \mathrm{C}$. The teeth were ground down to dentin from the buccal and the oral side using 330-grit silicon carbide paper on a polishing machine (LaboPol 21, Struers, Ballerup, Denmark), after which they were sectioned along the mesial-distal axis with a lowspeed diamond-bladed saw (Isomet, Buehler, IL, USA). Each half of the tooth was embedded in a circular mold with self-curing resin (Paladur, Heraeus Kulzer, Wehrheim, Germany). One half of the tooth underwent $\mathrm{pH}$ cycling, while the other half of the same tooth was left untreated as control. Six cycles per day involving 5-min demineralization and 3.5-h remineralization per cycle were applied. The $\mathrm{pH}$ of the solutions was checked periodically. The composition of the demineralization and remineralization solutions is listed in Table 1. Between demineralization and remineralization, the teeth were rinsed with demineralized water. Each erosion cycle of 8 days involved 20 tooth samples.

Afterwards the surfaces were prepared using one of the five preparation methods listed in Table 2.

\section{Micro-tensile bond strength testing}

The three-step etch-and-rinse adhesive OptiBond FL (O-FL; Kerr, Orange, CA, USA) and the mild two-step self-etch adhesive Clearfil SE Bond (C-SE; Kuraray, Tokyo, Japan) were evaluated (Table 3). The adhesives were applied following the respective manufacturer's instructions. On 16

Table 1 Composition of demineralization and remineralization solution ( $\mathrm{pH}$ cycling)

Solution Composition

(at $37^{\circ} \mathrm{C}$ )

Demineralization $1 \%$ citric acid with $\mathrm{pH}$ of 3.5

Remineralization $0.002 \mathrm{~g}$ ascorbic acid, $0.58 \mathrm{~g} \mathrm{NaCl}, 0.17 \mathrm{~g} \mathrm{CaCl}_{2}$, $0.16 \mathrm{~g} \mathrm{NH}_{4} \mathrm{Cl}, 1.27 \mathrm{~g} \mathrm{KCl}, 0.16 \mathrm{~g} \mathrm{NaSCN}$,

$0.33 \mathrm{~g} \mathrm{KH}_{2} \mathrm{PO}_{4}, 0.34 \mathrm{~g} \mathrm{Na}_{2} \mathrm{HPO}_{4}$ dissolved in 11 of demineralized water; $\mathrm{pH}$ is set to 6.4 with $\mathrm{HCl}$ samples (eight eroded, eight non-eroded) per preparation group, rectangular composite restorations (Tetric EvoCeram, Ivoclar Vivadent, Schaan, Liechtenstein; shade A3, batch no. L58159) were placed for micro-tensile bond strength testing $(\mu \mathrm{TBS})$. Thin sticks $(1 \times 1 \times 7 \mathrm{~mm})$ were sectioned with an automatic diamond-bladed saw (Accutom 50 , Struers). Whether the sticks originated from the mesial or distal part of the restoration or from the central part was recorded. Half of the specimens per tooth were analyzed after 24 -h water storage at $37^{\circ} \mathrm{C}$ (three to four sticks/specimen), whereas the other half were stored for 12 months in $0.5 \%$ chloramine solution at $37^{\circ} \mathrm{C}$ before being actually tested.

The specimens were fixed to a BIOMAT jig [15] with cyanoacrylate glue (Model Repair II, Dentsply-Sankrin, Ohtawara, Japan). The $\mu$ TBS test was performed at a crosshead speed of $1 \mathrm{~mm} / \mathrm{min}$ until fracture in a universal testing machine equipped with a load cell of $100 \mathrm{~N}$ (LRX, Lloyd, Hampshire, UK). The fractured area was determined by measuring the width and length of each specimen using a digital caliper (CD-15CPX, Mitutoyo, Kawasaki, Japan). The $\mu$ TBS was expressed in MPa as derived from dividing the imposed force $(\mathrm{N})$ at the time of fracture by the bond area $\left(\mathrm{mm}^{2}\right)$. Specimens that failed prior to testing (so-called pre-testing failure or ptf) were explicitly noted and were assigned as $0 \mathrm{MPa}$ in further analysis.

\section{Failure analysis by stereomicroscopy and Feg-SEM}

The fractured specimens were analyzed by stereomicroscopy (M5A, Wild, Heerbrugg, Switzerland) at a magnification of $\times 50$. Failures were determined as "adhesive" (interfacial failure), "cohesive in dentin," "cohesive in resin" (including failures within the composite or adhesive layer) or "mixed." After fracture analysis with the stereomicroscope, representative samples were prepared for fieldemission gun scanning electron microscopy (Feg-SEM, Philips XL30, Eindhoven, Netherlands) for a more precise analysis of the fracture mode.

Samples with the most frequent failure mode of each group were selected, fixed in $2.5 \%$ glutaraldehyde in cacodylate buffer solution, dehydrated in ascending concentrations of ethanol, and chemically dried using hexamethyldisilazane. The samples were mounted on aluminum stubs and goldsputter coated (Sputtering Device 07 120, Balzers Union, Balzers, Liechtenstein).

Interfacial analysis by transmission electron microscopy

For analysis of the adhesive-eroded dentin interfaces, two additional sticks were sectioned in a similar way as described for the $\mu$ TBS measurements. Per group, two specimens did not receive any further processing (non-demineralized), while two additional sticks were immersed in ammoniacal silver 
Table 2 Materials used for dentin surface preparation

\begin{tabular}{|c|c|c|c|}
\hline Group & Material & Manufacturer & Application method \\
\hline Pumice & $\begin{array}{l}\text { Bristle Hawe ZR } 835 \text { RA, } \\
\text { pumice slurry }\end{array}$ & Kerr Hawe, Orange, CA, USA & $\begin{array}{l}15 \mathrm{~s} \text {, without water spray, using blue- } \\
\text { banded handpiece }\end{array}$ \\
\hline Air abrasion & $\begin{array}{l}\text { Sandman, aluminum oxide } \\
\quad(25 \mu \mathrm{m})\end{array}$ & Sandman ApS, Aalborg, Denmark & $15 \mathrm{~s}$, close (at $1 \mathrm{~mm}$ ) to tooth surface \\
\hline Silicon polisher & $\begin{array}{l}\text { Brownie silicon carbide } \\
\text { polisher }(35-48 \mu \mathrm{m})\end{array}$ & Shofu, Kyoto, Japan & $\begin{array}{l}15 \mathrm{~s} \text {, with water spray, using blue-banded } \\
\text { handpiece }\end{array}$ \\
\hline Proxo-shape & $\begin{array}{l}\text { Proxoshape 100/514 }(40 \mu \mathrm{m}) \\
\text { Intra Lux Prophy } 61 \mathrm{LG}\end{array}$ & $\begin{array}{l}\text { Intensiv, Grancia, Switzerland; KaVo, } \\
\text { Biberach, Germany }\end{array}$ & $\begin{array}{l}15 \mathrm{~s} \text {, with water spray, using blue-banded } \\
\text { handpiece }\end{array}$ \\
\hline Diamond bur & Komet $842314014(100 \mu \mathrm{m})$ & Gebr. Brasseler, Lemgo, Germany & $\begin{array}{l}15 \mathrm{~s} \text { (ten strokes), with water spray, using } \\
\text { turbine }\end{array}$ \\
\hline
\end{tabular}

nitrate for the so-called nano-leakage evaluation [16]. All specimens were fixed in $2.5 \%$ glutaraldehyde in cacodylate buffer solution and dehydrated in ascending concentrations of ethanol prior to embedding in epoxy resin (Agar Scientific, Essex, UK), after which ultra-thin sections were cut (Ultracut UCT, Leica, Vienna, Austria). The specimens were evaluated unstained and positively stained (5\% uranyl acetate and saturated lead citrate) by transmission electron microscopy (TEM) (JEM-1200EX II, JEOL, Tokyo, Japan).

\section{Statistical analysis}

To assess the dentin bond strength data, a linear mixed effects model, taking into account the tooth that each specimen originated from, was constructed using statistical software (R 2.12.1 and nlme package, R Foundation for Statistical Computing, Vienna, Austria). In this model, all factors investigated and their first-order interactions were included. All tests were performed at a significance level of $\alpha=0.05$.

\section{Results}

Micro-tensile bond strength testing

Erosion significantly affected bond strength in all specimens $(p<0.001)$ (Tables 4 and 5). The adhesive had a significant influence on bond strength as well $(p=0.023)$. Comparing both adhesives, the three-step etch-andrinse adhesive O-FL bonded the best to control, noneroded dentin surfaces, whereas the two-step self-etch adhesive C-SE performed slightly better on eroded surfaces than O-FL. Storage significantly lowered bond strength for all specimens $(p<0.001)$, but this ageing effect was more prominent for the eroded specimens $(p<$ $0.001)$. Pre-testing failures were only observed in the most challenged groups when bonding to eroded dentin was combined with 1-year water storage. Finally, the surface preparation method also significantly influenced bond strength $(p<0.001)$.

Overall, the bond strength to eroded dentin was lower (Table 4), but all surface preparation methods resulted in an additional bond strength decrease as compared to the burcut control. Especially after 1-year water storage, the difference with other preparation methodologies was evident (Table 5).

Failure analysis using stereomicroscopy and Feg-SEM

For the immediate 24-h measurements, the bond strength of both adhesives was high, and therefore "cohesive" failures within resin were predominantly observed. However, storage clearly affected the bonding interface by reducing the amount of "cohesive" failures in favor of

Table 3 Composition of the adhesives tested

\begin{tabular}{|c|c|c|}
\hline Adhesives & Composition & Application \\
\hline \multirow[t]{3}{*}{$\begin{array}{l}\text { O-FL OptiBond FL } \\
\text { (Kerr, Orange, CA, USA) }\end{array}$} & Etching [452301]: 37.5\% phosphoric acid, silica thickener & $\begin{array}{l}\text { Etch for } 15 \mathrm{~s} \text {, rinse for } 15 \mathrm{~s} \text {, gently } \\
\text { air-dry for } 5 \mathrm{~s}\end{array}$ \\
\hline & Primer [2888409]: HEMA, GPDM, PAMM, ethanol, water, photoinitiator & Scrub the surface for $15 \mathrm{~s}$ with Primer \\
\hline & $\begin{array}{l}\text { Adhesive [2921936]: TEG-DMA, UDMA, GPDM, HEMA, Bis-GMA, } \\
\text { filler, photoinitiator }\end{array}$ & $\begin{array}{l}\text { Apply a thin coat of adhesive and } \\
\text { light-cure for } 30 \mathrm{~s} \text {. }\end{array}$ \\
\hline \multirow[t]{2}{*}{$\begin{array}{l}\text { C-SE Clearfil SE Bond } \\
\text { (Kuraray, Tokyo, Japan) }\end{array}$} & $\begin{array}{l}\text { Primer [00868B]: 10-MDP, HEMA, hydrophilic dimethacrylate, } \\
\text { di-camphorquinone, } N, N \text {-diethanol-p-toluidine, water }\end{array}$ & Apply primer for $20 \mathrm{~s}$, mild air stream \\
\hline & $\begin{array}{l}\text { Bond [01274B]: 10-MDP, bis-GMA, HEMA, hydrophobic dimethacrylate, } \\
\text { di-camphorquinone, } N, N \text {-diethanol-p-toluidine, silanated colloidal silica }\end{array}$ & $\begin{array}{l}\text { Apply bond, gentle air stream, } \\
\text { light-cure for } 10 \mathrm{~s}\end{array}$ \\
\hline
\end{tabular}


Table 4 Micro-tensile bond strength in MPa (mean) with standard deviations $( \pm \mathrm{SD})$

\begin{tabular}{|c|c|c|c|c|c|c|c|c|}
\hline \multirow[t]{2}{*}{ Surface preparation } & \multirow[t]{2}{*}{ Adhesive } & \multirow[t]{2}{*}{ Dentin } & \multicolumn{3}{|c|}{ 24-h storage } & \multicolumn{3}{|c|}{ 1-year storage } \\
\hline & & & $n$ & $\mathrm{ptf}$ & $\mu \mathrm{TBS}(\mathrm{SD})$ & $n$ & $\mathrm{ptf}$ & $\mu \mathrm{TBS}$ (SD) \\
\hline \multirow[t]{4}{*}{ Pumice } & \multirow[t]{2}{*}{ O-FL } & Eroded & 31 & 0 & $33.4(12.6)$ & 30 & 15 & $8.4(14.8)$ \\
\hline & & Non-eroded & 31 & 0 & $46.5(13.7)$ & 30 & 0 & $36.3(10.9)$ \\
\hline & \multirow[t]{2}{*}{ C-SE } & Eroded & 32 & 0 & $33.1(9.5)$ & 31 & 6 & $10.4(13.4)$ \\
\hline & & Non-eroded & 29 & 0 & $41.1(13.6)$ & 31 & 0 & $30.9(12.6)$ \\
\hline \multirow[t]{4}{*}{ Air abrasion } & \multirow[t]{2}{*}{ O-FL } & Eroded & 31 & 0 & $29.1(14.5)$ & 31 & 12 & $5.2(8.9)$ \\
\hline & & Non-eroded & 31 & 0 & $42.5(10.5)$ & 30 & 0 & $38.6(10.0)$ \\
\hline & \multirow[t]{2}{*}{ C-SE } & Eroded & 30 & 0 & $31.6(10.5)$ & 31 & 11 & $7.1(11.8)$ \\
\hline & & Non-eroded & 31 & 0 & $39.5(11.6)$ & 32 & 0 & $31.5(14.6)$ \\
\hline \multirow[t]{4}{*}{ Silicon polisher } & \multirow[t]{2}{*}{ O-FL } & Eroded & 32 & 0 & $28.3(7.1)$ & 32 & 22 & $1.5(3.1)$ \\
\hline & & Non-eroded & 30 & 0 & $33.5(9.3)$ & 30 & 0 & $41.0(12.0)$ \\
\hline & \multirow[t]{2}{*}{ C-SE } & Eroded & 32 & 0 & $28.3(9.9)$ & 32 & 7 & $3.5(4.9)$ \\
\hline & & Non-eroded & 31 & 0 & 30.5 (13.6) & 31 & 0 & $25.8(12.2)$ \\
\hline \multirow[t]{4}{*}{ Proxo-shape } & \multirow[t]{2}{*}{ O-FL } & Eroded & 31 & 0 & $31.5(7.5)$ & 31 & 23 & $0.4(1.5)$ \\
\hline & & Non-eroded & 30 & 0 & $44.9(10.7)$ & 31 & 0 & $33.5(10.5)$ \\
\hline & \multirow[t]{2}{*}{ C-SE } & Eroded & 31 & 0 & $32.0(11.7)$ & 31 & 12 & $2.8(4.3)$ \\
\hline & & Non-eroded & 31 & 0 & $37.7(10.9)$ & 31 & 0 & $25.0(10.2)$ \\
\hline \multirow[t]{4}{*}{ Diamond bur } & \multirow[t]{2}{*}{$\mathrm{O}-\mathrm{FL}$} & Eroded & 31 & 0 & $36.3(13.1)$ & 31 & 6 & $21.1(17.3)$ \\
\hline & & Non-eroded & 31 & 0 & $38.8(12.1)$ & 32 & 0 & $25.2(12.3)$ \\
\hline & \multirow[t]{2}{*}{ C-SE } & Eroded & 32 & 0 & $33.2(12.4)$ & 29 & 1 & $16.1(14.2)$ \\
\hline & & Non-eroded & 31 & 0 & $34.6(11.8)$ & 32 & 0 & $20.2(9.2)$ \\
\hline
\end{tabular}

$n$ number of specimens, $p t f$ pre-testing failure (all $\mathrm{ptfs}$ were related to 1-year storage)
Interfacial analysis by TEM

Erosion increased the hybrid layer thickness, what obviously hampered a proper infiltration of the adhesive resin. After 1-year storage, all specimens appeared more prone to interface detachment during specimen processing, rendering proper interface characterization more difficult. Overall,

Fig. 1 SEM photomicrographs of $\mu$ TBS-fractured surfaces of Optibond FL (Kerr) specimens. a "Mixed" failure with major part having failed "cohesively" after 24-h water storage. b One-year storage changed clearly the fracture pattern into an 'adhesive' failure mode. Resin penetration into the demineralized (eroded) dentin was poor as the failure occurred within the hybrid layer. c Proxo-shape (Intensiv) preparation resulted in a "cohesive" failure pattern after 24-h storage, involving failure within the adhesive resin as well as restorative composite. d Failure pattern after 1-year water storage again turned into an "adhesive" failure mode as in b. Failure within the hybrid layer. e Diamond bur preparation resulted in a "cohesive" failure type after $24 \mathrm{~h}$. However, this specimen included a "cohesive" failure within dentin as well as a "cohesive" failure within resin. f One-year storage turned the "cohesive" failure pattern into an "adhesive" one. However, compared to $\mathbf{b}$ and $\mathbf{d}$, this failure mostly occurred at the top of the hybrid layer. Furthermore, some resin remnants that failed "cohesively" are detectable as well. g Only one edge of the stick failed "adhesively" for this non-eroded specimen. Most of the surface remained covered by composite. h The surface percentage "adhesive" failure increased after 1-year storage. However, hybridization seemed to hold out better for the non-eroded specimens as the fracture pattern occurred predominantly near the top of the hybrid layer 


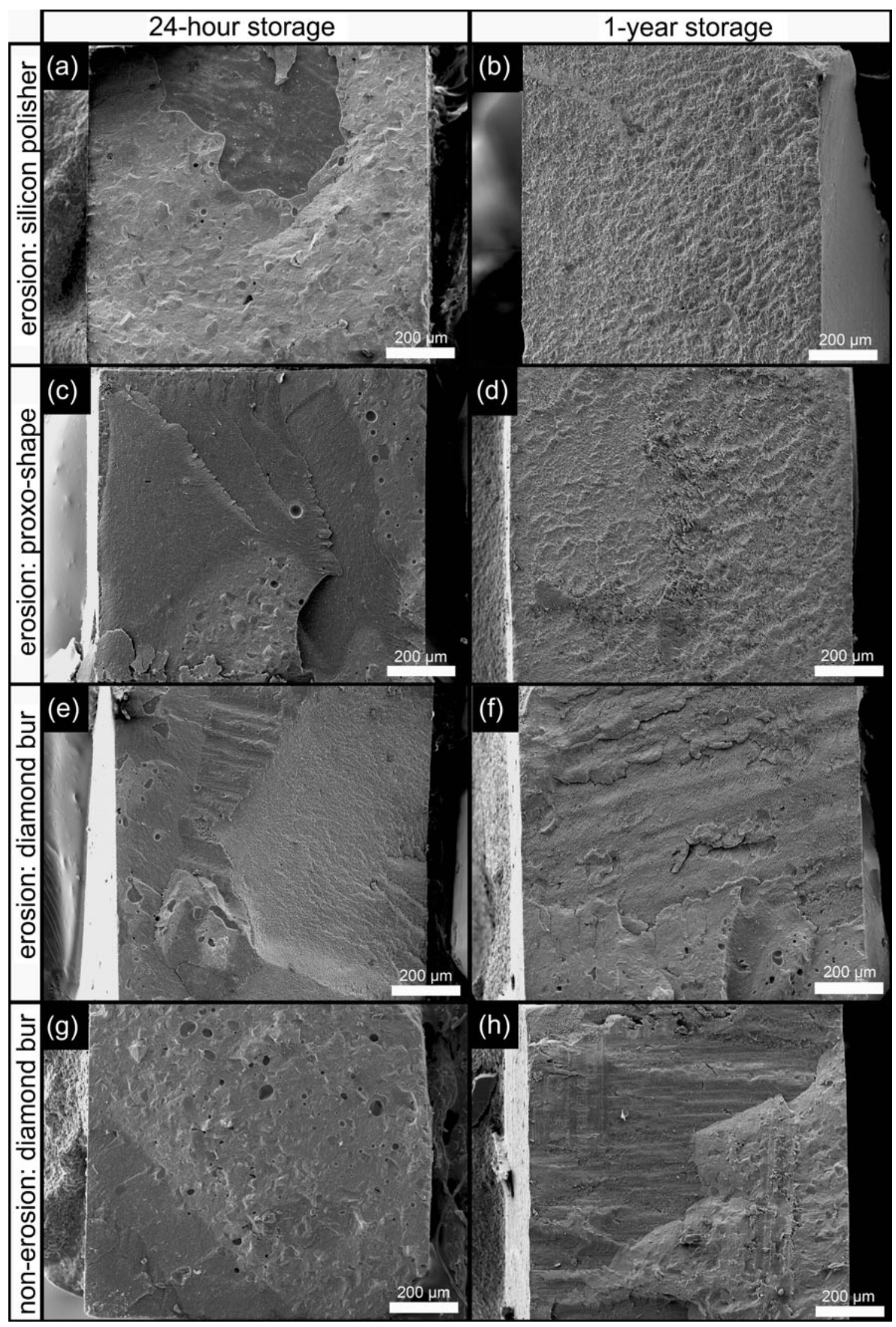




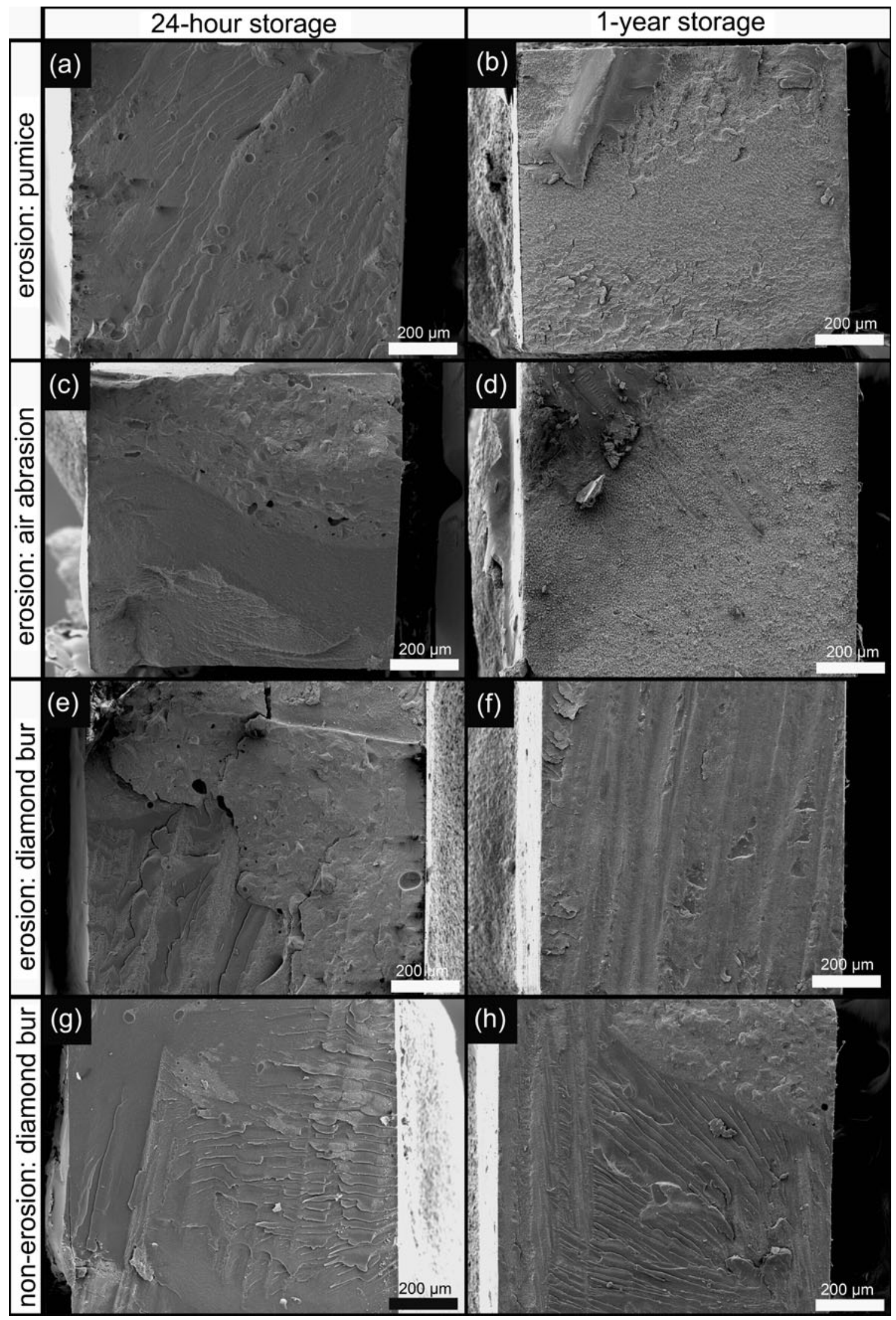


Fig. 2 SEM photomicrographs of $\mu$ TBS-fractured surfaces of Clearfil SE Bond (Kuraray) specimens. a Pumice cleaning of eroded dentin resulted in an overall "cohesive" failure pattern after 24-h water storage. b One-year storage turned the failure type into an "adhesive" one. The adhesive failure occurred at different levels of the hybrid layer, indicating that the by-erosion exposed collagen fibrils were poorly enveloped by resin. c Air abrasion revealed a "mixed" failure type composed of all types of failure, such as "cohesive in resin," "cohesive in dentin," and "adhesive." $\mathbf{d}$ Similar change in failure mode after 1year storage as in b: "adhesive" failure within the hybrid layer. e Diamond bur preparation resulted in a "cohesive" failure type within the adhesive as well as composite. f Although the incidence of "adhesive" failure was increased after 1-year storage, the surface seemed still to be covered by adhesive resin and the hybrid layer seemed to be less prone to fracture than in the case where other surface preparation methods were used. $\mathbf{g}$ Non-eroded diamond bur specimen that failed "cohesively." h One-year storage of non-eroded specimens was clearly less affected by ageing of the interface than in the case of eroded specimens

the ultra-morphologic interfacial features hardly differed for the different surface preparation techniques employed, except for the diamond bur preparation that appeared to have removed the demineralized (eroded) dentin layer quite effectively (Figs. 3 and 4).

Poor resin infiltration was confirmed by enhanced silver deposition (nano-leakage), which was always higher for the eroded than for the non-eroded specimens. Furthermore, the sections prepared from the 1-year water-stored (eroded) specimens became less stainable, indicating that the exposed collagen fibrils were severely affected by ageing.

The etch-and-rinse adhesive O-FL resulted in an outer dentin zone of $7-10 \mu \mathrm{m}$ in depth that was nearly completely demineralized. When O-FL was applied to eroded dentin, the outer demineralized dentin zone was increased to a thickness of 10 to $17 \mu \mathrm{m}$. TEM clearly revealed that the more invasive the surface preparation technique employed, the smaller the thickness of the resultant hybrid layer became. Interestingly, even pumice appeared relatively effective to remove the outer zone of demineralized (eroded) dentin. Nevertheless, the additional demineralization effect of $\mathrm{pH}$ cycling appeared only to be removed by diamond bur preparation.

The self-etch adhesive C-SE showed very clearly the effect the erosion simulation had on the dentin surface. Whereas its hybrid layer is normally thinner than $1 \mu \mathrm{m}$, the zone of demineralized dentin was increased up to $15 \mu \mathrm{m}$. However, dentin was mostly not completely demineralized as some hydroxyapatite crystals still remained around the tubules. One-year water storage clearly affected the interface, as was revealed by a significantly higher amount of bond failures and enhanced silver deposition. Regarding surface preparation techniques, clear differences in micro-structure were found between eroded and non-eroded specimens, except when a diamond bur was employed.

\section{Discussion}

This investigation showed that the way eroded dentin was prepared clearly influenced the bonding effectiveness of two representative adhesives. Both working hypotheses therefore had to be rejected as (1) there were significant differences in bond strength to eroded versus non-eroded dentin surfaces for the different surface-preparation techniques tested, and (2) this effect was most prominent for the eroded specimens, although most test groups showed a clear decrease in bonding effectiveness after 1-year water storage.

The $\mathrm{pH}$ cycling used in this study to simulate erosion in vitro is a quite common approach that has been applied previously [17-19]. This treatment resulted in a loss of minerals, exposed collagen fibrils, and opened dentin tubules. The changes in surface characteristics induced by the artificial erosion process are in accordance with those reported previously [17]. Ultramorphologically, TEM revealed that the outer dentin surface was completely demineralised, with some hydroxyapatite crystals only remaining around the dentinal tubules. This naturally should be attributed to peritubular dentin that is somewhat less susceptible to demineralization than intertubular dentin.

Although still today the so-called immediate bonding effectiveness is mostly measured, long-term bonding performance, after the specimens have been exposed to a kind of artificial ageing, provides much more information in the prediction of the clinical lifetime of adhesive restorations [20]. Nevertheless, water ageing of micro-specimens is a very challenging procedure as the interface within the tiny micro-specimen is directly exposed to water and therefore easily penetrated. It was shown before that demineralized and insufficiently resin-coated collagen fibrils are very prone to hydrolytic degradation [21, 22]. In this study, adequate hybridization of the deeply eroded dentin surface appeared difficult, as was confirmed by the significantly reduced bond strength measured after 1-year water storage. The by-erosion thicker layer of exposed collagen could hardly be infiltrated by the adhesive. This should most likely be attributed to collapse of the demineralized collagen fibrils and to its higher water content that prevented the adhesive not only to infiltrate fully but probably also to polymerize properly. Such hybridization inefficiency enhanced nanoleakage and consequently accelerated bond degradation $[23,24]$. This is further supported by the more prominent failure of micro-specimens within the hybrid layer after 1-year water storage, as was observed by SEM after bond strength testing, and by the enhanced silver deposition, as by TEM in particular for the eroded dentin specimens.

The actual bonding effectiveness to eroded dentin also depended on the adhesive tested in this study. The etch-andrinse adhesive showed a superior bonding performance onto non-eroded (control) dentin surfaces, to which it also remained bonded effectively after 1-year water ageing. Although onto eroded dentin surfaces the self-etch adhesive 


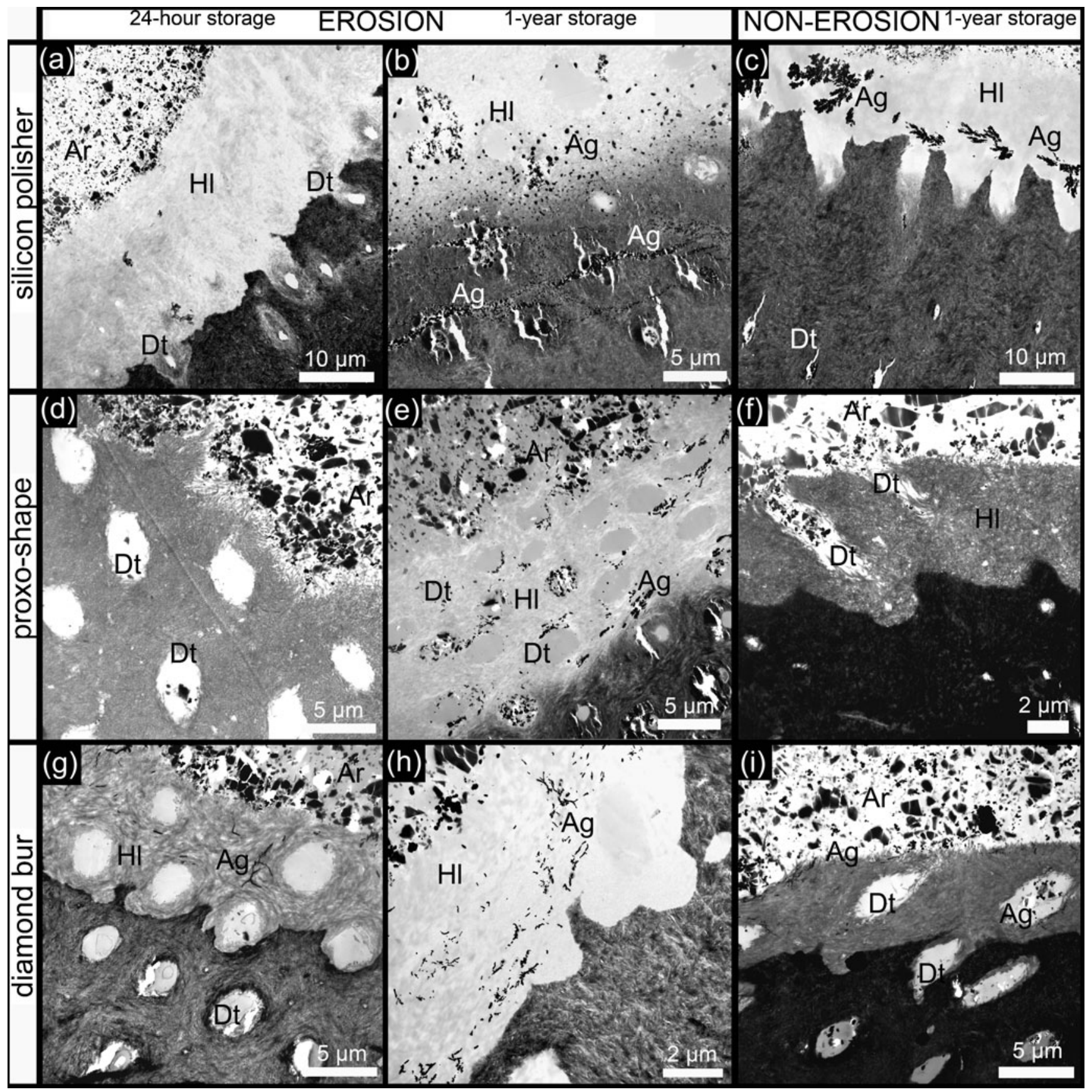

Fig. 3 TEM photomicrographs of OptiBond FL (Kerr) specimens. a The use of a silicon polisher did not sufficiently reduce the depth of demineralized (eroded) dentin. Consequently, the hybrid layer thickness was still larger than that typically observed for the noneroded control in c. b The poor hybridization made the interface at eroded dentin very sensitive to degradation, as was confirmed by the relatively heavy silver deposition. Silver uptake was most prominent in the hybrid layer at the transition zone from the completely demineralised to the more densely mineralized dentin. $\mathbf{c}$ The non-eroded (control) specimen showed localized silver deposition after 1-year storage, while the hybrid layer thickness was clearly smaller than that in a. d Collagen fibrils were largely exposed after preparation with Proxoshape (Intensiv), as was also confirmed by the positively stained specimens. e The central and bottom part of the hybrid layer appeared most susceptible for silver deposition after 1-year storage. $\mathbf{f}$ The positively stained non-eroded (control) specimen resulted in a densely organized collagen-fibril structure with some exposed fibrils d. g Diamond bur preparation of eroded dentin resulted in an almost similar interfacial ultrastructure as that observed for the non-eroded control $\mathbf{i}$. h Removal of the most demineralized outer dentin zone resulted in a better long-term bonding performance, as was revealed by the less prominent silver deposition after 1-year water storage. i Nevertheless, the non-eroded specimen still revealed less silver deposition (1-year storage). $\mathrm{Ag} \mathrm{AgNO}$ deposition, $\mathrm{Ar}$ adhesive resin, $\mathrm{Dt}$ dentin tubule, $\mathrm{Hl}$ hybrid layer 


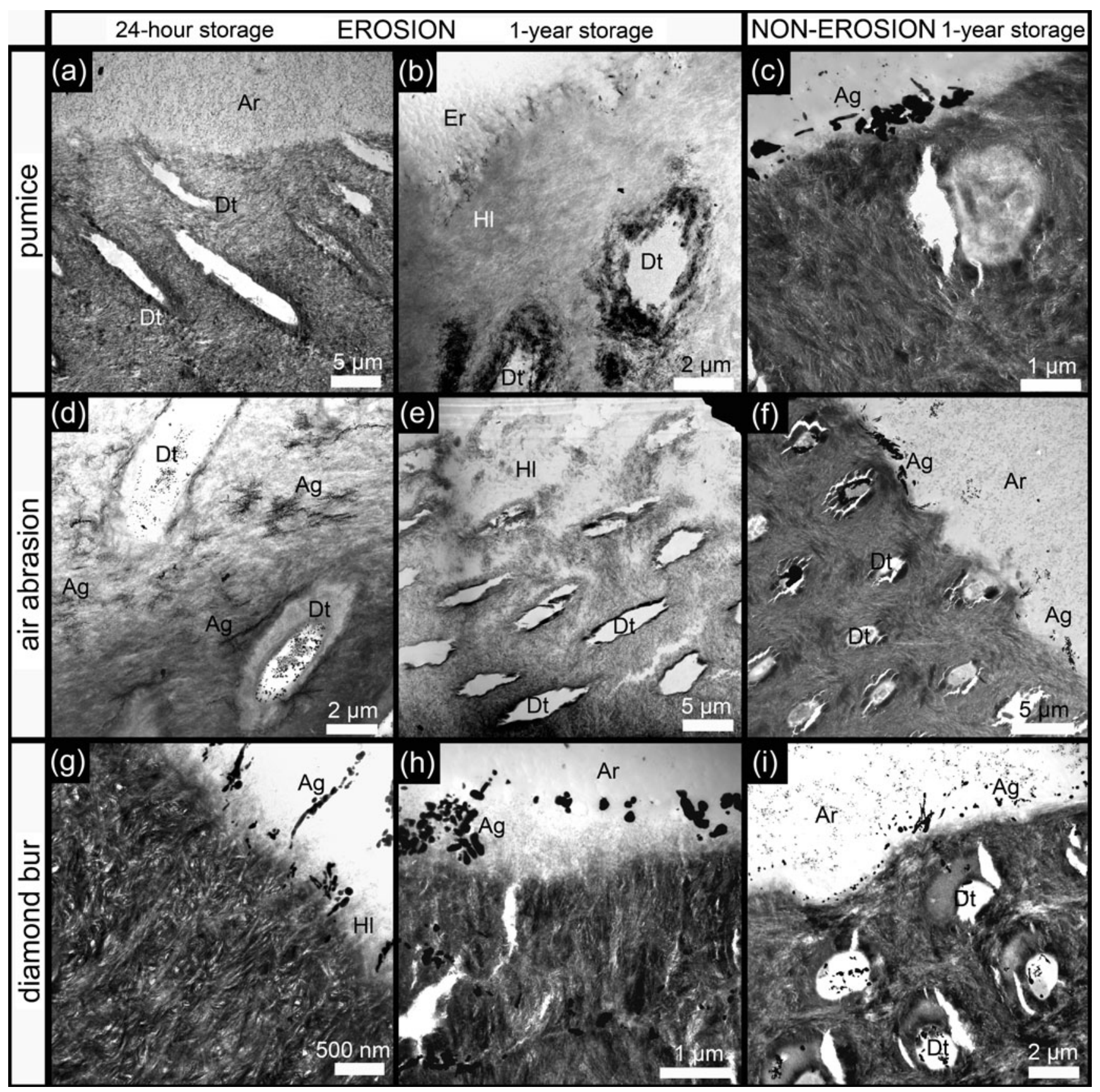

Fig. 4 TEM photomicrographs of Clearfil SE Bond (Kuraray) specimens. a Scrubbing the surface with pumice appeared to have been quite effective to remove the most outer zone of the demineralized (eroded) dentin. The remaining, more poorly mineralized dentin clearly disclosed residual hydroxyapatite crystals. b One-year storage highly affected the interface, as was evidenced by severely affected collagen fibrils. This became especially clear as the exposed collagen zone appeared much less stainable with heavy metals. The bond degradation also made specimen processing more difficult as interface detachment was more often experienced. c After 1-year storage, the non-eroded (control) specimen revealed only few and localized areas of silver deposition. d Air abrasion almost did not change the micro-structure of the eroded specimen as also a wide zone of demineralized (eroded) dentin remained. The many areas where silver was deposited, around the tubules and within the hybrid layer, indicate that resin had not infiltrated the eroded dentin surface sufficiently. e One-year storage resulted in increased interface detachment and collagen fibrils that appeared severely affected by water storage ageing. f After 24$\mathrm{h}$ water storage, much less nano-leakage was detected in the hybrid layer, as what appeared from the rather limited silver deposition. $g$ Diamond bur preparation again reduced the hybrid layer thickness to that typically observed for the control (non-eroded) specimens. Some localized silver deposition however remained detectable. h One-year storage showed good performance in TEM regarding silver deposition. Even the underlying dentin zone seemed normally mineralized, though some silver-infiltrated areas could be detected as well. i At non-eroded dentin, 1-year storage revealed rather limited silver deposition, mainly appearing as small spot-like infiltrations in the hybrid layer. $\mathrm{Ag} \mathrm{AgNO}_{3}$ deposition, $A r$ adhesive resin, $D t$, dentin tubule, $E r$ embedding resin, $H l$ hybrid layer 
performed slightly better, the bond strength was clearly reduced after 1-year water storage for both adhesives. This is in accordance with other studies that reported a lower bond strength of etch-and-rinse adhesives to demineralized dentin $[11,25,26]$. The application of phosphoric acid on eroded dentin resulted in a completely demineralized outer dentin zone that gradually became more mineralized towards the inner part and eventually changed into normal mineralized dentin. For the self-etch adhesive, some residual hydroxyapatite crystals were found around the dentinal tubules and may have stabilized the hybrid layer more and/or prevented collagen from completely collapsing.

The way of surface preparation had a significant influence on bonding performance. The different preparation techniques investigated were chosen in order to investigate how invasive the preparation should be to achieve good long-term bonding to eroded dentin. Therefore, the different surface preparation techniques investigated varied in invasiveness from simply surface "cleaning" with pumice (1), over air abrasion using $25 \mu \mathrm{m} \mathrm{Al}_{2} \mathrm{O}_{3}$ (2), mechanical rotary instrumentation using a silicon polisher (35-48 $\mu \mathrm{m}$ grit size) (3), and mechanical oscillating instrumentation using fine-grit (40 $\mu \mathrm{m}$ grit size) diamond-coated files (4) to surface roughening using a $100-\mu \mathrm{m}$ grit-size diamond bur. The 24-h "immediate" bond strength of the etch-and-rinse adhesive was not significantly influenced by the preparation method, which corresponds to earlier findings of other investigations $[12,13,27]$. Phosphoric acid relatively aggressively etches dentin, thereby dissolving thick and compact smear layers as well. In contrast to the relative insensitivity of the etch-and-rinse adhesive tested, the bonding effectiveness of the self-etch adhesive appeared much more to depend on the way the eroded (and non-eroded) dentin surface was prepared. The "mild" self-etch adhesive tested does not completely remove the smear layer but dissolves it partially, while the adhesive penetrates simultaneously [28]. It was shown before that surface finishing with a fine-grit diamond bur promotes the bonding effectiveness of mild self-etch adhesives [12, 13, 29]. In this study, TEM revealed clear differences in the removal of demineralized (eroded) dentin by the various surface-preparation techniques applied. Differences in hybridization efficiency associated with the surface preparation methodology employed became most apparent after the 1-year water ageing. Whereas O-FL confirmed his well-known superiority in long-term bond strength to "normal" non-eroded dentin, it performed clearly less effectively onto eroded dentin. A significantly lower bond strength correlated well with a high amount of ptfs in this group. The lowest bond strength was recorded when the eroded dentin was prepared by Proxo-shape (Intensiv) and the silicon polisher (Brownie, Shofu). This could be directly related to a less effective removal of demineralized (eroded) dentin. In general, the self-etch adhesive underperformed the etch-andrinse adhesive when bonded to eroded dentin but nevertheless presented with higher bond strength than O-FL after 1-year ageing. The high decrease in bond strength to eroded dentin after ageing was corroborated by TEM that revealed enhanced nano-leakage (silver deposition) and less stainable collagen fibrils. The latter lower stainability should be related to a decreased amount of polar groups available along the collagen fibril to absorb the heavy metal [30]. Only for bur preparation, O-FL revealed higher bond strength. One could conclude that grit size alone is not the only determinant to achieve sufficient bond strength, as air abrasion and pumice cleaning revealed higher bond strength than Proxo-shape (Intensiv) preparation. The smear layer thickness and removal properties for demineralized dentin seemed therefore to be important for the self-etching adhesive.

\section{Conclusion}

Long-term bonding to eroded dentin was clearly affected by the way the eroded dentin surface was prepared. A minimally invasive cavity preparation approach should clinically always be strived for. Nevertheless, superficial preparation (or minimal roughening) with a diamond bur is highly recommended to adhesively restore erosion lesions.

Acknowledgment B. Zimmerli holds a grant of the Swiss National Science Foundation (PBBEP3-123608). The authors thank all manufacturers for donating the restorative materials used in this study. The authors thank Timothy Mutsvari from I-Biostat, Katholieke Universiteit Leuven, for his statistical advice.

Conflicts of interest The authors declare that they have no conflict of interest.

Open Access This article is distributed under the terms of the Creative Commons Attribution Noncommercial License which permits any noncommercial use, distribution, and reproduction in any medium, provided the original author(s) and source are credited.

\section{References}

1. Myklebust S, Espelid I, Svalestad S, Tveit AB (2003) Dental health behavior, gastroesophageal disorders and dietary habits among Norwegian recruits in 1990 and 1999. Acta Odontol Scand 61:100-104

2. Karamanolis G, Sifrim D (2007) Developments in pathogenesis and diagnosis of gastroesophageal reflux disease. Curr Opin Gastroenterol 23:428-433

3. Waterhouse PJ, Auad SM, Nunn JH, Stehen IN, Moynihan PJ (2008) Diet and dental erosion in young people in south-east Brazil. Int J Paediatr Dent 18:353-360

4. Brunton PA, Kalsi KS, Watts DC, Wilson NH (2000) Resistance of two dentin-bonding agents and a dentin desensitizer to acid erosion in vitro. Dent Mater 16:351-355

5. Azzopardi A, Bartlett SW, Watson TF, Sheriff M (2001) The measurement and prevention of erosion and abrasion. J Dent 29:295-400 
6. Sundaram G, Wilson R, Watson TF, Bartlett D (2007) Clinical measurement of palatal tooth wear following coating by a resin sealing system. Oper Dent 32:539-543

7. Azzopardi A, Bartlett DW, Watson TF, Sheriff M (2004) The surface effects of erosion and abrasion on dentine with and without a protective layer. Br Dent J 96:341-354

8. Federlin M, Thonemann B, Schmalz G, Urlinger T (1998) Clinical evaluation of different adhesive systems for restoring teeth with erosion lesions. Clin Oral Investig 2:58-66

9. Brackett WW, Brackett MG, Dib A, Franco G, Estudillo H (2005) Eighteen-month clinical performance of a self-etching primer in unprepared class $\mathrm{V}$ resin restorations. Oper Dent 30:424-429

10. Rocha PI, Borges AB, Rodrigues JR, Arrais CA, Giannini M (2006) Effect of dentinal surface preparation on bond strength of self etching adhesive systems. Braz Oral Res 20:52-58

11. Sattabanasuk V, Vachiramon V, Qian F, Armstrong SR (2007) Resin-dentin bond strength as related to different surface preparation methods. J Dent 35:467-475

12. Ermis RB, De Munck J, Cardoso MV, Coutinho E, van Landuyt KL, Poitevin A, Lambrechts P, Van Meerbeek B (2008) Bond strength of self-etch adhesives to dentin prepared with three different diamond burs. Dent Mater 24:978-985

13. Cardoso MV, Coutinho E, Ermis RB, Poitevin A, Van Landuyt K, De Munck J, Carvalho RCR, Van Meerbeek B (2008) Influence of dentin cavity surface finishing on micro-tensile bond strength of adhesives. Dent Mater 24:492-501

14. Yiu CKY, Hirashi N, King NM, Tay FR (2008) Effect of dentinal surface preparation on bond strength of self-etching adhesives. J Adhes Dent 10:173-182

15. Poitevin A, De Munck J, Van Landuyt K, Coutinho E, Peumans M, Lambrechts P, Van Meerbeek B (2007) Influence of three specimen fixation modes on the micro tensile bond strength of adhesives to dentin. Dent Mater J 26:694-699

16. Tay FR, Pashley DH, Yoshiyama M (2002) Two modes of nanoleakage expression in single-step adhesives. J Dent Res 81:472-476

17. Ganss C, Schlueter N, Hardt M, von Hinckeldey J, Klimek J (2007) Effects of toothbrushing on eroded dentine. Eur J Oral Sci 115:390-396

18. Francisconi LF, Honório HM, Rios D, Maghalães AC, Machado MAAM, Buzalaf MAR (2008) Effect of $\mathrm{pH}$ cycling on different restorative materials and on enamel restored with these materials. Oper Dent 33:203-208
19. Maghalães AC, Rios D, Moino AL, Wiegand A, Attin T, Buzalaf MAR (2008) Effect of different concentrations of fluoride in dentifrices on dentin erosion subjected or not to abrasion in situ/ ex vivo. Caries Res 42:112-116

20. Van Meerbeek B, Peumans M, Poitevin A, Mine A, Van Ende A, Neves A, De Munck J (2010) Relationship between bond-strength tests and clinical outcomes. Dent Mater 26:e100-e121

21. Hashimoto M, Ohno H, Kaga M, Endo K, Sano H, Oguchi H (2000) In vivo degradation of resin-dentin bonds in humans over 1 to 3 years. J Dent Res 79:1385-1391

22. De Munck J, Van Landuyt K, Peumans M, Poitevin A, Lambrechts P, Braem M, Van Meerbeek B (2005) A critical review of the durability of adhesion to tooth tissue: methods and results. J Dent Res 84:118-132

23. Sano H, Takastu T, Ciucchi B, Horner JA, Matthews WG, Pashley DH (1995) Nanoleakage: leakage within the hybrid layer. Oper Dent 20:18-25

24. Hashimoto M, Ohno H, Sano H, Kaga M, Oguchi H (2003) Degradation patterns of different adhesives and bonding procedures. J Biomed Mater Res 66B:324-330

25. Hara AT, Queiroz CS, Giannini M, Cury JA, Serra MC (2004) Influence of the mineral content and morphological pattern of artificial root caries lesion on composite resin bond strength. Eur J Oral Sci 112:67-72

26. Schmidlin PR, Siebenmann J, Kocher P, Seemann R, Attin T, Bindl A (2008) Effects of de- and remineralization of dentin on bond strengths yielded by one-, three, and four step adhesives. J Adhes Dent 10:119-126

27. De Oliveira MT, de Freitas PM, de Paula EC, Ambrosano GM, Giannini M (2007) Influence of diamond sono-abrasion, airabrasion and Er:YAG laser irradiation on bonding of different adhesive systems to dentin. Eur J Dent 1:158-166

28. Mine A, De Munck J, Cardoso MV, Van Landuyt KL, Poitevin A, Kuboki T, Yoshida Y, Suzuki K, Van Meerbeek B (2010) Enamelsmear compromises bonding by mild self-etch adhesives. J Dent Res 89:1505-1509

29. Oliveira SS, Pugach MK, Hilton JF, Watanabe LG, Marshall SJ, Marshall GW Jr (2003) The influence of the dentin smear layer on adhesion: a self-etching primer vs. a total etch system. Dent Mater 19:758-767

30. De Munck J, Van Meerbeek B, Yoshida Y, Inoue S, Vargas M, Suzuki K, Lambrechts P, Vanherle G (2003) Four-year water degradation of total-etch adhesives bonded to dentin. J Dent Res 82:136-140 